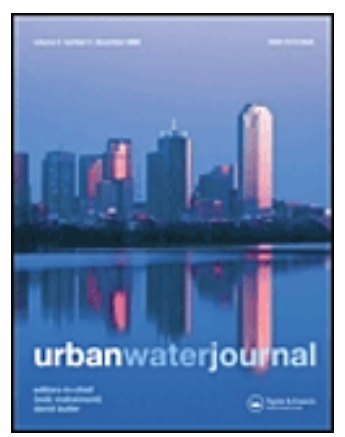

\title{
Discharge coefficients for specific grated inlets. Influence of Froude number
}

\begin{tabular}{|c|c|}
\hline Journal: & Urban Water Journal \\
\hline Manuscript ID & NURW-2019-0136.R4 \\
\hline Manuscript Type: & Research Article \\
\hline $\begin{array}{r}\text { Date Submitted by the } \\
\text { Author: }\end{array}$ & $\mathrm{n} / \mathrm{a}$ \\
\hline Complete List of Authors: & $\begin{array}{l}\text { Cosco, Chiara; Universitat Politècnica de Catalunya, } \\
\text { GÓMEZ, MANUEL; Department of Civil and Environmental Engineering } \\
\text { (DECA) - FLUMEN Institute of River Dynamics and Hydrological } \\
\text { Engineering, Universitat Politècnica de Catalunya } \\
\text { Russo, Beniamino; Group of Hydraulic and Environmental Engineering } \\
\text { (GIHA), Technical College of La Almunia (EUPLA), University of Zaragoza } \\
\text { Tellez-Alvarez, Jackson; Department of Civil and Environmental } \\
\text { Engineering (DECA) - FLUMEN Institute of River Dynamics and } \\
\text { Hydrological Engineering, Universitat Politècnica de Catalunya } \\
\text { Macchione, Francesco; , Department of Environmental and Chemical } \\
\text { Engineering - LaMPIT (Laboratorio di Modellistica numerica per la } \\
\text { Protezione Idraulica del Territorio), University of Calabria } \\
\text { Costabile, Pierfranco; Department of Environmental and Chemical } \\
\text { Engineering - LaMPIT (Laboratorio di Modellistica numerica per la } \\
\text { Protezione Idraulica del Territorio), University of Calabria } \\
\text { Costanzo, Carmelina; Department of Environmental and Chemical } \\
\text { Engineering - LaMPIT (Laboratorio di Modellistica numerica per la } \\
\text { Protezione Idraulica del Territorio), University of Calabria }\end{array}$ \\
\hline Keywords: & $\begin{array}{l}\text { Discharge coefficient, Froude number, grate inlet, inlet efficiency, real- } \\
\text { scale experiment, urban drainage }\end{array}$ \\
\hline
\end{tabular}

\section{SCHOLARONE" Manuscripts}




\begin{abstract}
BENIAMINO RUSSO, researcher and professor, Group of Hydraulic and Environmental Engineering
\end{abstract} (GIHA), Technical College of La Almunia (EUPLA), University of Zaragoza, Zaragoza, Spain

Email:beniamino.russo@upc.edu

JACKSON TELLEZ-ALVAREZ, PhD., Department of Civil and Environmental Engineering (DECA) FLUMEN Institute of River Dynamics and Hydrological Engineering, Universitat Politècnica de Catalunya, Barcelona, Spain

Email: jackson.david.tellez@upc.edu

FRANCESCO MACCHIONE, full professor, Department of Environmental and Chemical Engineering - LaMPIT (Laboratorio di Modellistica numerica per la Protezione Idraulica del Territorio), University of Calabria, Cosenza, Italy

Email:francesco.macchione@unical.it

PIERFRANCO COSTABILE, researcher and professor, Department of Environmental and Chemical Engineering - LaMPIT (Laboratorio di Modellistica numerica per la Protezione Idraulica del Territorio), University of Calabria, Cosenza, Italy

Email:pierfranco.costabile@unical.it 
CARMELINA COSTANZO, researcher, Department of Environmental and Chemical Engineering LaMPIT (Laboratorio di Modellistica numerica per la Protezione Idraulica del Territorio), University of Calabria, Cosenza, Italy

Email: carmelina.costanzo@unical.it

Running Head (i.e. the text that appears in the top margin of the published page): Discharge coefficients for specific grate inlets 


\section{Introduction}

The main function of the drainage network is to guarantee the protection of urban activities during rain events.

One of the main consequences due to the rapid and intense urbanization is the increase of the amount of impermeable surfaces (Fletcher et al., 2013). This process, in turn, causes a significant modification of the hydrological response of the basins, leading to a greater and faster runoff in respect to rural catchments (Huang et al., 2008), low groundwater recharge (Simmons \& Reynolds, 1982) and the increase of occurrence of flood event (Braud et al., 2013).

When the rainfall event is intense, runoff must be intercepted by inlets and introduced into the sewer network. If not removed from streets, roads or curbs, runoff generates risk to pedestrians, above all elderly and children, threshold values of water depth and velocity are reached, vehicles begin to slide or float, representing risk for pedestrians and other vehicles.

In order to reduce the hazard for people and vehicles, the grate inlet efficiency and their location play an important role in draining the superficial runoff. Therefore, there is the need to provide an accurate description of these structures within modelling tools for hazard assessment (Russo et al., 2013). A correct inlet spacing, as such as the choice of adequate grated inlets types, plays a main role in guaranteeing efficiency of the whole drainage system, avoiding flood risk for people and vehicles circulation and the correct functioning of our cities during extreme storm events (Gómez et al., 2009; Gómez et al., 2011).

In urban flood analysis, the dual drainage approach is frequently considered for the modeling of urban flooding (Tsang-Jun et al., 2018). This idea considers a combined analysis of the surface system, represented by the streets and city ground, and the underground layer, composed by the sewer system. During a rain event, significant flow transfers can be activated from the two systems. In particular, during the evolution of the 
rainfall event, flow exchange goes from the surface to the sewer and later, if the discharge capacity of the sewer conduit is exceeded, from the sewer to the surface level. So, the flow transfer analysis becomes a key element and this is usually done assuming weir or orifice type expressions for the flow through inlets. For example, the user manual of InfoWorks suggests to set, in case of grate inlets, the orifice discharge coefficient equal to 0.67 , that is the same value assumed as found for instance in textbooks for orifices in a tank (Innovyze, 2019 ,), and in case or weir type equation, suggested discharge coefficients range from 1.25 to 1.66. Another example is the value suggested by the Neenah Foundry, one of the manufacturers of inlets based in USA, where in the website they present an orifice type calculator, and the proposed discharge coefficient is 0.6 , similar as the value indicated in InfoWorks (Neenah Foundry, 2018), for weir type equation the coefficient proposed is 3.3 (imperial units) similar to value 3 (imperial units) proposed by InfoWorks.

In several practice manuals or recommendations, the intercepted flow is considered as an orifice with discharge coefficient equal to 0.6 (Txdot, 2018) (SSCAFCA, 2018) but there is no reference to laboratory tests or measurements to verify this coefficient is correct value. The same can be found in the Urban Drainage Manual of Denver, where a discharge coefficient value of 0.67 is suggested (2006). In the Drainage manual of the Dep. of Irrigation and drainage of the Ministry of Water, land and Natural resources (2018), discharge coefficient value, 0.6 , is suggested.

Therefore, all these technical suggestions do not consider the hydrodynamic conditions of the street runoff during the flood event and, in particular, local values of water depths and velocities, which are different to the hydraulics of a tank (zero velocity). On the other hand, those equations are being used to represent something that is quite far away from the theoretical concept of an orifice or a weir. Hence, coefficients derived for these idealized conditions may not be appropriate.

In the authors' opinion and considering some previous studies developed at UPC (Gómez \& Russo, 2005), those approaches that use uncalibrated range of values have evident limitations and, therefore, experimental research is needed to provide suitable values, depending on the street flow hydraulics that are strongly influenced by the specific features of the rainfall events.

\section{Theoretical background}

Flow passing a grate inlet was studied since the first half of the last century. One of the authors who first treated the phenomenon in detail was Mostkow (1957), who formulated the equations to define the flow profile passing over a bottom grate. This discharge was found to be depended on a discharge coefficient related to bars' geometry, specific energy of the flow and geometric parameters.

Later, the discharge coefficient was studied by Subramanya \& Sengupta (1981), who modified Mostkow's equation to consider specific energy of the flow. They provided mathematical equations to express the discharge coefficient for several flow and slope conditions.

In the recent times, discharge relationships have been amply used within the flooding model context. Examples 
are given by Chen et al. (2007) and Djordjevic et al. (2005).

Insufficient research about discharge coefficient has been stated by Djordjevic et al. (2005) as the main cause for high uncertainty in the intercepted discharge simulation. The best way to describe water interception by a drainage grid would be through three-dimensional modeling, not 1D or 2D because, when water travels through interception elements, its movement assumes pronounced three-dimensional features. Three-dimensional phenomena affecting drainage elements include surcharge at the sewer as well (Balmforth et al., 2006). Therefore, some numerical studies focused on 3D description of the flow intercepted by inlets and around them (Leandro et, 2016; Gómez et al, 2016), due to the changes of the flow direction when it is intercepted. But this approach takes too much CPU time to simulate the 3D behavior in practical flood modeling studies. Hence simple approaches of 1D flow are normally considered to describe the amount of flow intercepted by the inlet, assuming an orifice or a weir approach.

Due to the higher awareness towards urban flood issues and related risks for pedestrians and vehicles, in recent years the interest of many authors has focused on the urban flooding and exchange equations. Therefore, from the general study of water over bottom grids, investigation has been oriented towards flow behavior on urban drainage elements (Gómez \& Russo, 2005). In particular, the response of the urban catchment to intense rainfall events and inlet efficiency has assumed a key role in prevention from flood damages (Gómez et al., 2011a; Russo et al., 2013a).

Among the most recent studies focused on urban flooding and grate capacity, Kemper \& Schlenkhoff (2019) proposed a formula able to calculate grates efficiency and hydraulic capacity when supercritical flow condition is achieved. Another recent study was conducted by Rubinato et al. (2018), who focused on circular inlets with different grate designs in sub critical flow conditions, in order to obtain discharge coefficients adopting both orifice and weir approaches.

Several experimental studies concerning urban grate inlet efficiency have been conducted at the Universitat Politècnica de Catalunya by FLUMEN Research Institute, considering different values of transverse and longitudinal slope (Gómez \& Russo, 2005).

The intercepted discharge $Q_{i n t}$ can be expressed by equation 1, considering an orifice approach to represent the grate inlet, depending on the discharge coefficient, void area and upstream energy available:

$$
Q_{\text {int }}=\mu_{\mathrm{o}} \cdot \varphi \cdot A_{T} \cdot \sqrt{2 \cdot g \cdot E}
$$

Where $Q_{i n t}$ represents intercepted discharge by the inlet in case of orifice approach to describe the grate inlet, $\varphi$ is the a percentage of void area of the inlet, $E$ is the water energy upstream the grate (sum of the depth and velocity head), $A_{T}$ is the total area of the grate and $g$ stands for gravity acceleration. If we remember the application of this expression to a tank emptying, the energy $E$ is usually considered only as the water level above the center of the orifice (Coutinho de Lencastre, 1998). Flow conditions where we apply the orifice expression in our case is not the same as in other hydraulic applications.

It is useful also to remark that in the common applications of flow interchange between surface and sewer systems, urban flood models consider energy $\mathrm{E}$ as water depth only in orifice and weir equations. This is the case, for example, of Infoworks ICM (Innovyze, 2019; Russo et al., 2015). 
Instead, considering a weir approach, the intercepted discharge is defined by equation 2 :

$$
Q_{\text {int }}=\frac{2}{3} \cdot \mu_{\mathrm{w}} \cdot \sqrt{2 \cdot g} \cdot L \cdot E^{3 / 2}
$$

Where $Q_{\text {int }}$ represents intercepted discharge by the inlet, $\mu_{\mathrm{w}}$ is the discharge coefficient of the inlet considered as a weir, $E$ is water energy upstream the grate, $L$ is the effective length of the weir equal to the length plus the width of the inlet, and $g$ stands for gravity acceleration. It may be argued that effective length depends on the flow pattern around the grate. Some researchers have considered the weir length as the total length of the grill within the grate. For example, Rubinato et al. (2018) defined it as effective edge perimeter (obtained by AutoCAD drawings prior to fabrication) but, in their formula, they used the diameter of the circular inlet.

For subcritical conditions, the effective length it may be estimated as the sum of the grate length plus twice its width. Instead, for the cases we will analyze here (supercritical condition), the sum of length and width has been considered more appropriate. Basically, it infers that downstream side of the grate does not contribute to the intercepted discharge. It is important to observe that the definition of the effective length reported above is irrespective of the grate design, lumping together the differences in void space and energy loss parameter. Anyway, in this study, a sensitivity analysis has been performed in order to check how results vary according to effective length choice. The results are shown in the section of results.

A laboratory study was made by Mustaffa et al. (2006) about some of the manholes and inlets of the city of Edmonton (Canada). Results presented state that discharge coefficient for the orifice was around 0.616. These tests considered ponding situations (with Froude number from 0.3 to 2.2 ) and the authors concluded these coefficients decrease, however, with an increase in the Froude number of the flow if there is a channel flow over the cover elements.

Experimental campaigns have been realized by Rubinato et al. (2017), who provided new values for discharge coefficient. Rubinato et al. (2017) presented a range of values for discharge coefficients in weir and orifice equations, in order to represent properly interactions between sewer system and surface flows through manhole elements without lids during urban flood events in subcritical conditions. For discharge coefficient in weir equation, the authors obtained an interval between 0.493 and 0.587 , while for the orifice equation, discharge coefficient varied from 0.159 to 0.174 . On the other hand, for different grate designs in sub critical flow conditions, Rubinato et al. (2018) obtained discharge coefficients varied from 0.115 to 0.372 for the weir equation, and from 0.349 to 2.038 for the orifice approach.

The present study differs from the previous ones because it aims to research drainage grate inlets and not manholes, to provide a useful tool to select the drainage element capable to intercept as much runoff as possible, by analyzing both orifice and weir approaches to represent grate inlets. It can be observed, also, the significant difference in terms of approaching and captured flows used in this experimental campaign compared to other studies. For example, in this experimental campaign tests were carried out over a range of approaching flow between 25 and $200 \mathrm{l} / \mathrm{s}$ (equivalent to a unit width discharge between 8.3 and $66.7 \mathrm{l} / \mathrm{sm}$ ) while tests presented by Rubinato et al. (2018) were completed over a range of surface inflows between 4 and $10 \mathrm{l} / \mathrm{s}$ (equivalent to a unit width discharge between 1 and $2.5 \mathrm{l} / \mathrm{s}$ ). The study carried out by Kemper and 
Schlenkhoff (2019) considered an approaching flow between 3 and $21 \mathrm{l} / \mathrm{s}$ corresponding to a unit widt discharge between 2 and 14 approximately.

Moreover, it should be observed that direct comparison to specific values proposed in the previously reported experimental studies will not be possible unless geometrical properties (weir length etc.) are defined in an identical manner.

The experimental campaign shown here refers to three grate models and for all of them the discharge coefficient variation has been represented as a function of the Froude number corresponding to the approaching flow immediately upstream the inlet.

\section{Methodology}

3.1

\section{Experimental equipment}

The experimental campaign has been conducted in the hydraulic laboratory of the Universitat Politècnica de Catalunya (Technical University of Catalonia), in Barcelona (Spain) (Figure 1). The purpose of this campaign was simulating water behavior on several models of urban grates, in order to study their efficiency and possible relationships between efficiency and hydraulic parameters.

\section{[Figure 1 about here]}

The water is pumped through a system of pipes, able to raise a maximum discharge of $250 \mathrm{l} / \mathrm{s}$. The metallic platform, which represents an urban street, is 4 meters wide and 5.5 meters long. The useful area for experimental tests is 3 meters wide and 5 meters long (Figure 2). Two PVC walls define the useful area for experiments. The wall close to the grid reproduces curb limit because in Barcelona drainage grate inlets are in uniform curbs with triangular shape. Since it is a real scale platform, the outcomes obtained in tests are quite realistic and not subjected to uncertainty due to scale effects. Particularly, circulating flow considered during tests are quite similar to the flow produced by heavy rains on a road lane and real dimensions of the platform and the tested grates avoid typical scale effects due to surface tension in scaled models.

Platform slope can change in longitudinal (from 0 to 10\%) and transversal (from 0 to $4 \%$ ) directions respect to flow.

\section{[Figure 2 about here]}

Before entering the platform, the water is stored in a reservoir. It has the role to dissipate the energy from the water approaching the platform. When the water begins flowing on the platform, water depth distribution is very similar to a flow distribution that takes place in a street characterized by same geometry and slope. 
Laboratory tests have been conducted setting 5 different discharge values and changing longitudinal and transversal slopes in order to simulate the runoff due to 5 different rainfall events in streets characterized by different geometry. Discharge values tested in this experimental campaign are: 25, 50, 100, 150 and 200 L/s. Transversal slope values are: 0,2 and $4 \%$.

Longitudinal slope values are: $0,0.5,1,2,4,6,8,10 \%$. Therefore, for any discharge, 24 tests have been conducted.

Then, for each combination of slopes and discharge, water depth has been manually measured in the points of interest immediately upstream the grate, with a limnimeter of $0.1 \mathrm{~mm}$ accuracy (Russo et al., 2013).

In order to be more specific, the measures have been taken one centimeter upstream the grate. The uncertainties of these water depth measures may be quantified in a millimeter, also due to the presence of flow waves in some cases it can reaches few millimeters. In order to calculate velocities, approaching discharge has been measured according to what has been reported in Russo et al. (2013). The approaching discharge, then, have been measured by a flowmeter and the obtained measures have been considered very reliable since the flowmeter uncertainty has been estimated in 1-2 1/s, which is really not relevant in our experimental campaign because the least approaching flow used is $50 \mathrm{l} / \mathrm{s}$.

In order to calculate cross sectionally averaged velocity values, wet area values have been found using trigonometry notions. In order to be more specific, it is worth to explain that cross sections corresponding to the grate can assume rectangular, triangular and trapezoidal shapes, depending on the transversal slope values. Finally, using approaching flow and wet area values, the cross sectionally averaged velocity of the approaching flow has been found, for each one of the considered areas.

This procedure is quite common in experimental studies (Kawanishi et al., 2009). Moreover, as demonstrated by recent studies on the use of surface flow image velocimetry technique to analyze flow approaching grated inlets carried out to this physical model, numerical velocity distribution is quite uniform and similar to crosssection average velocity (Tellez-Álvarez et al., 2019). Therefore, the values of velocity estimated as described above can be considered as cross-sectional average velocities.

Discharge coefficient-Froude number relationship

From the experimental data set, and considering equation 1 and 2, we have obtained the discharge coefficients for every combination of approaching flow and transverse and longitudinal geometry.

We can use several ways to present the dataset of orifice and weir discharge coefficients, but for a better application, we preferred to represent them as a function of the characteristics of the approaching flow. We selected Froude number to describe it, as a dimensionless number.

Discharge coefficient-Froude number relationships are proposed for three studied grate inlet models, known as: Barcelona1, E-25 and Meridiana. The first two grate inlets have diagonal bars and different size, while the Meridiana grate has transverse bars and size quite similar to Barcelonal geometry (Figure 3 and Table 1). 
where $\mathrm{Fr}$ represents the Froude number of the approaching flow, $v$ is flow cross sectionally averaged velocity, $S$ and $W$ are respectively cross section area and top width of the approaching flow and $g$ is gravity acceleration. Then, intercepted discharge equation 1 and 2 have been applied to obtain discharge coefficients in both cases, assuming grate inlets behave as orifice or weir. Geometric data of the three grate models are reported in Table 1.

\section{[Table 1 about here]}

Froude number and discharge coefficient values have been plotted and possible equations representing discharge coefficient as a function of Froude number have been found. After that, the validation process has been conducted for all grate models. Equations 2 and 3 have been used to calculate discharge coefficient values for the experimental data sets saved to validate (different from the data set used to find the relationships). In order to do that, again experimental intercepted discharge values have been used. Finally, discharge coefficient and Froude number values have been reported in graphs in order to complete the validation process.

\section{Results}

\subsection{Results analysis and validation for the orifice approach}

For the orifice type equation, discharge coefficient values found in the three grates vary approximately from 0.4 to 0.1 or less (Table 2), close to one third of the proposed values found in Neenah (2018) and InfoWorks (2018). Moreover, we have observed relevant variations on the values depending of the 
approaching flow characteristics, and we try to define the variation of the discharge coefficients as a function of the type of flow.

Potential relationships between discharge coefficient and Froude number of the approaching flow are presented for the three grate models analyzed in the present study, when the grate inlet is considered as an orifice or as a weir. Furthermore, full experimental data used during the present study have been included in the appendix. In all tested cases a potential law between discharge coefficients and Froude values seems adequate to describe the situation.

For Barcelona1 grate, potential correlation between discharge coefficient and Froude number, using the orifice approach is described through equation 4 :

$$
\mu_{\mathrm{o}}=0.4239 \cdot \mathrm{Fr}^{-1.006}
$$

Where $\mu_{0}$ represents the discharge coefficient and Fr is the Froude number. The decreasing of discharge coefficient with Froude can be seen, arriving for the highest Froude values to very small coefficients in all cases below 0.1. In the following graph we can observe the goodness of the adjustment of this potential correlation (Figure 4).

\section{[Figure 4 about here]}

For grid E-25, potential correlation is expressed by equation 5 .

$$
\mu_{\mathrm{o}}=0.4737 \cdot \mathrm{Fr}^{-0.826}
$$

where $\mu_{\mathrm{o}}$ represents the discharge coefficient and $\mathrm{Fr}$ is the Froude number. This potential correlation has been plotted in Figure 5.

\section{[Figure 5 about here]}

The last analyzed grate inlet is Meridiana model. In this case, the discharge coefficient can be expressed through potential equation 6 , as it was found for the other two grate models. Figure 6 represents this potential adjustment to real data.

$$
\mu_{0}=0.418 \cdot \operatorname{Fr}^{-0.906}
$$

\section{[Figure 6 about here]}

In all 3 cases a reduction of discharge coefficient with Froude number of the approaching flow is observed. The Froude variation is really high, from 1 to 14 , approximately, covering basically supercritical flow conditions. The experimental data used to find these potential relationships corresponds to two-thirds of the whole experimental set of values.

The range values of discharge coefficient showed in the previous graphs have been reported in Table 2 . In order to get a comparison of discharge coefficient ranges for the three analyzed inlets, values correspond to the same Froude number (particularly minimum and maximum values).

\section{[Table 2 about here]}

As it is highlighted by the obtained results, discharge coefficients values are lower than the ones usually used for grate inlets. Apart from this, the present study has provided different values depending on the grate inlet, underlining the importance of experimental studies to characterize the interception capacity of these important elements of the drainage systems. The experimental campaign demonstrated that the discharge coefficient 
The same procedure applied in paragraph 2.4 has been repeated considering the grate inlets as weir elements, characterized by an effective length equal to the sum of the two sides that allow water to be intercepted. For Barcelona1, the potential correlation that relates discharge coefficient to Froude number, obtained using equation 2 , is described by equation 7 .

$$
\mu_{\mathrm{w}}=0.6593 \cdot \mathrm{Fr}^{-1.899}
$$

where $\mu_{\mathrm{w}}$ represents the discharge coefficient and Fr is the Froude number. The adjustment defined by this equation 7 , is reported in the following figure 8 .

\section{[Figure 8 about here]}

For grid E-25, potential correlation is expressed by equation 8 .

$$
\mu_{\mathrm{w}}=0.505 \cdot \mathrm{Fr}^{-1.692}
$$

where $\mu_{\mathrm{w}}$ represents the discharge coefficient and Fr is the Froude number. This potential correlation has been plotted in Figure 9, where it is clear that, as the orifice approach, also the weir represents properly the flow on the grate inlet.

\section{[Figure 9 about here]}


The last analyzed grate inlet is Meridiana model. In this case, the discharge coefficient can be expressed through potential equation 9 in case of weir assumption. Figure 10 represents this potential adjustment to real data.

$$
\mu_{\mathrm{w}}=0.4237 \cdot \mathrm{Fr}^{-1.794}
$$

\section{[Figure 10 about here]}

As it is possible to note, the graphs show significant deviation between proposed relationships and datasets for lower Froude numbers.

The range values of discharge coefficient showed in the previous graphs have been reported in Table 3 . Also in this approach, as it has been done for the orifice, the ranges have been defined for the common minimum and maximum Froude values in order to be able to compare them.

\section{[Table 3 about here]}

Also in this case, discharge coefficients values are lower than the ones usually used for grate inlets. Concerning the weir coefficients, proposed values in the International System found in the InfoWorks are between 0.42 to 0.54 , for depressed and undepressed inlets that compared with the values from the experiments, 0.28 and less than 0.01, again are quite different. If we apply the values found in the technical literature, for instance considering the flow transfers in a dual drainage approach, we can have serious differences between our calculations and the reality. That's another reason to study in detail the discharge coefficients. As it has been done for orifice approach, also the results obtained considering the grate inlet as a weir have been validated to demonstrate that there is a good correspondence between discharge coefficients calculated introducing experimental intercepted discharges in equation 2 and the potential correlations corresponding to this weir approach.

The data used for validation corresponds to a third part of the whole experimental data set, as it has been done for orifice approach validation. Therefore, for the three grate models, experimental values have been used to calculate discharge coefficients by applying equation 2 . Then, these values have been compared to the potential curves obtained in this same paragraph. The validation analysis has demonstrated that this second approach is successful and discharge coefficient- Froude number correlation is valid.

\section{[Figure 11 about here]}

Effective length of the weir depends on the flow pattern around the grate. For very small longitudinal slopes, it may be estimated as the sum of the grate length plus twice its width. Instead, for the cases we will analyze here (supercritical conditions), the sum of length and width has been considered more appropriate. It has been found that the results of this sensitivity analysis, considering the two definitions of effective length, are less than $25 \%$ in terms of discharge coefficient values. Results of the sensitivity analysis for any grate inlet are reported in Table 5 .

\section{[Table 5 about here]}

5. 
The present work contributes to fill a gap existing in the knowledge of discharge coefficients for urban grate inlets, in case of supercritical flow conditions. It is a sensitive issue because of the always more frequent urban floods due to climate change and uncontrolled urbanization. The dual drainage approach considering the join behavior of the major and minor systems (street flow and sewer flow) interactions, has as a key element the flow transfers between both systems through the set of inlets. So, to develop a good approach, the correct assessment of these flow transfers is extremely relevant.

In this study, experimental campaigns have been conducted to search the values of the discharge coefficients of three inlets of the city of Barcelona, in supercritical flow condition and for grates that are fully covered by water.

Geometry of the grate is generally different for every model, and shapes could be extremely different, including longitudinal, transversal or diagonal bars. For the orifice it is clear that the parameter considered is the void area, as a representative of the hydraulics, and for weir it was considered a combination of frontal plus lateral length of the weir. The purpose of this paper is to simplify these effects on the hydraulic efficiency and focus on the discharge coefficient the dependency of different shapes and sizes of the grate inlets analyzed. For Barcelona1 model, a suitable range of values varies from 0.055 to 0.294 when the inlet is considered as an orifice but the lower thresholds changes when weir assumption is done, with discharge coefficients between 0.009 and 0.244 . For Meridiana model, the upper extreme of the range is a little bit shifted upwards, with values that go from 0.033 to 0.431 using the orifice approach and discharge coefficients from 0.003 and 0.245 for weir approach. In the end, E-25 grid is characterized by discharge coefficients between 0.054 and 0.423 when it is considered as an orifice, while the suitable interval goes from 0.006 to 0.286 using the weir hypothesis.

In general, it can be observed that the weir coefficients are much more variable than the orifice ones.

In order to have a quick idea of the performances of the three analyzed grate models, the results for the three of them corresponding to specific value of approaching flow and slope conditions are reported in Table 4 . The considered flow for this comparison is equal to $150 \mathrm{~L} / \mathrm{s}$, while transversal and longitudinal slopes are respectively $2 \%$ and $6 \%$. As it may be noted, the highest discharge coefficient value corresponds to Barcelona 1 grate model, while the lowest interception corresponds to Meridiana grate model.

Comparing the obtained values with the ones suggested by some manufacturer or commercial software, the differences is 10 times one in front the other.

The ranges defined in this study have been compared with those found by Rubinato et al. (2018), who got higher minimum and maximum values using the weir equation to represent the grate inlet performance, while with the orifice approach, the minimum range value is higher respect to the range presented in this paper, while the maximum one is lower. In any case, the ranges for the discharge coefficients for both approaches (orifice and weir approach) are significantly lower than the commonly ones used in literature.

Comparing the correlation coefficients $\mathrm{R}^{2}$ obtained for orifice and weir approaches, it is possible to state that higher correspondences ( $\mathrm{R}^{2}$ more than 0.9 ) have been achieved for the second approach (weir approach), 
although in the other case values from 0.81 up to 0.88 have also been obtained. Due to the better correlation coefficients obtained for the three studied grate models applying a weir approach, it would be more appropriate to use this approach in order to get discharge coefficient values. It is useful to observe that there is significant variation between model and data as flow approaches subcritical conditions, therefore close to unitary Froude number. Future work may be about finding new relationship in order to describe properly the situation.

To conclude, it is possible to notice that each grate model presents different discharge coefficient values because they are characterized by different geometrical features. Therefore, studying intercepted discharge, and then efficiency, just by picking a value from a general range of discharge coefficient values would provide sensible error to flow intercepted estimation and likely practical problems due to an unexpected behavior of the drainage elements during intense rainfall events. Additional future studies should extend experimental campaigns to other grates models in order to define accurate discharge coefficient values for each of them and considering reverse flow, flow leaving the sewer to the street in case of pressurized systems. 


\section{References}

Balmforth, D., Digman, C., Kellagher, R., \& David, B. (2006). Designing for exceedance in urban drainage: good practice. (London: CIRIA, Ed.).

Braud, I., Breil, P., Thollet, F., Lagouy, M., Branger, F., Jacqueminet, C., ... Michel, K. (2013). Evidence of the impact of urbanization on the hydrological regime of a medium-sized periurban catchment in France. Journal of Hydrology, 485, 5-23. https://doi.org/10.1016/j.jhydrol.2012.04.049

Chen, A. S., Djordjević, S., Leandro, J., \& Savić, D. A. (2007). The urban inundation model with bidirectional flow interaction between 2D overland surface and 1D sewer networks. Novatech 2007, 465-472. https://doi.org/2042/25250

Coutinho de Lencastre, A., (1998). Manual de Ingeniería Hidráulica. Universidad Pública de Navarra/Nafarroako Unibertsitate Publikoa. Translation by Camilo Robles García.

Ministry of water, Land and Natural Resources, Department of irrigation and Drainage (2018). Urban Stormwater Management Manual For Malaysia (Manual Saliran Mesra Alam)-MSMA. https://www.water.gov.my/index.php/pages/view/579?mid=269.

Denver Storm Drainage Criteria Manual (2006). Storm Drainage design and technical criteria. United states.

Djordjevic, S., Prodanovic, D., Maksimovic, C., Ivetic, M., \& Savic, D. (2005). SIPSON-Simulation of Interaction between Pipe flow and Surface Overland flow in Networks. Water Science and Technology, 52(5), 275-283.

Fletcher, T. D., Andrieu, H., \& Hamel, P. (2013). Understanding, management and modelling of urban hydrology and its consequences for receiving waters: A state of the art. Advances in Water Resources, 51, 261-279. https://doi.org/10.1016/j.advwatres.2012.09.001

Gómez M., Macchione F., Russo B. (2009). Hydraulic behavior of urban streets during storm events. Ingenieria Hidraulica en Mexico, vol. 24, p. 51-62, ISSN: 0186-4076

Gómez, M., Macchione, F., \& Russo, B. (2011). Methodologies to study the surface hydraulic behaviour of urban catchments during storm events. Water Science and Technology, 63(11), 2666-2673. https://doi.org/10.2166/wst.2011.174

Gómez, M., \& Russo, B. (2005). Comparative study of methodologies determine inlet efficiency from test data. HEC-12 methodology vs UPC method. Water Resources Management, Algarve, Portugal., 80, 623632. https://doi.org/10.2495/WRM050621 
Gómez, M., \& Russo, B. (2011a). Methodology to estimate hydraulic efficiency of drain inlets. Water Management, 164(2): 81-90. DOI: 10.1680/wama.900070.

Huang, H., Cheng, S., Wen, J., \& Lee, J. (2008). Effect of growing watershed imperviousness on hydrograph parameters and peak discharge. Hydrological Processes, 22, 2075-2085.

Innovize (2019). InfoWorks ICM (Integrated Catchment Modeling) v.10. User Manual References. https://www.innovyze.com/en-us/news-insights/infoworks-icm-100-released-by-innovyze.

Kemper, S., \& Schlenkhoff, A. (2019). Experimental study on the hydraulic capacity of grate inlets with supercritical surface flow conditions. Water Science and Technology. 79(9), 1717-1726. https://doi.org/10.2166/wst.2019.171

Kawanishi, K., Kaneko, A., Razaz, M., Abe, T., (2009). Measurement of Cross-Sectional Average Velocity in a Shallow Tidal River with a Next-GenerationAcoustic Velocity Meter. In: Advances in Water Resources and Hydraulic Engineering. Springer, Berlin, Heidelberg.

Mostkow, M., A. (1957). A theoretical study of bottom type water intakes. (L. H. Blanche, Ed.).

Mustaffa Z., Rajaratnam N., Zhu D. Z. (2006). An experimental study of flow into orificies and grating inlets on streets. Canadian Journal of Civil Engineering (NRC Research Press, 33, 7, 837.

Neehah Foundry (2018). Manual of Engineering tools \& calculations.

Rubinato, M., Martins, R., Kesserwani, G., Leandro, J., Djordjević, S., \& Shucksmith, J. (2017). Experimental calibration and validation of sewer/surface flow exchange equations in steady and unsteady flow conditions. Journal of Hydrology, 552, 421-432. https://doi.org/10.1016/j.jhydrol.2017.06.024

Rubinato, M., Lee, S., Martins, R., \& Shucksmith, J. (2018). Surface to sewer flow exchange through circular inlets during urban flood conditions. Journal of Hydroinformatics, 20 (3),564-576.

Russo, B., Gómez, M., Macchione, F. (2013). Pedestrian hazard criteria for flooded urban areas. Natural Hazards 69:251-265 DOI 10.1007/s1 1069-013-0702-2.

Russo B., Gómez M. \& Tellez J. (2013). Methodology to Estimate the Hydraulic Efficiency of Nontested Continuous Transverse Grates. Journal of Irrigation and Drainage Engineering, 139(10), 864-871. DOI: 10.1061/(ASCE)IR.1943-4774.0000625.Russo B., Sunyer D., Velasco M., Djordjevíc S. (2015). Analysis of extreme flooding events through a calibrated 1D/2D coupled model: the case of Barcelona (Spain). Journal of Hydroinformatics.IWA publishing. Vol. 17, No. 3, 473-491 (2015). DOI: 10.2166/hydro.2014.063. 
Simmons, D. L., \& Reynolds, R. J. (1982). Effects of Urbanization on Base Flow of Selected South-Shore Streams, Long Island, New York. JAWRA Journal of the American Water Resources Association, 18(5), 797-805. https://doi.org/10.1111/j.1752-1688.1982.tb00075.

Southern Sandoval County Arroyo Flood Control Authority (SSCAFCA) (2018). Development Process Manual, Hydraulic Design. https://www.sscafca.org/development-process-manual/.

Subramanya, K., \& Sengupta, D. (1981). Flow through bottom racks. Indian Journal of Technology, 19, 64 67.

Tellez-Alvarez J, Gómez M, Russo B and Redondo JM. Using surface flow image velocimetry to analyse flow approaching grated inlets. Proceedings of the Institution of Civil Engineers - Water Management, https://doi.org/10.1680/jwama.18.00103

Texas Department of Transportation (TxDOT) (2018). Hydraulic Design Manual. http://onlinemanuals.txdot.gov/txdotmanuals/hyd/manual_notice.htm.

Tsang-Jung C., Chia-Ho W., Chen A., Djordjevic S. (2018). The effect of inclusion of inlets in dual drainage modelling. Journal of Hydrology, 559, 541-555. https://doi.org/10.1016/j.jhydrol.2018.01.066. 
Table 1

\begin{tabular}{llll}
\hline & $\boldsymbol{\varphi}$ & $\mathrm{B}(\mathrm{m})$ & $\mathrm{L}(\mathrm{m})$ \\
\hline Barcelona1 & 0.553 & 0.260 & 0.745 \\
E-25 & 0.421 & 0.300 & 0.640 \\
Meridiana & 0.454 & 0.300 & 0.800
\end{tabular}

Table 2

Potential relationship values for orifice approach

\begin{tabular}{llll} 
& Barcelona 1 & E-25 & Meridiana \\
\hline Min & 0.055 & 0.054 & 0.033 \\
Max & 0.294 & 0.423 & 0.431
\end{tabular}

Table 3

\begin{tabular}{|c|c|c|c|}
\hline \multicolumn{4}{|c|}{ Potential relationship values for weir approach } \\
\hline & Barcelona 1 & E-25 & Meridiana \\
\hline Min & 0.009 & 0.006 & 0.003 \\
\hline Max & 0.244 & 0.286 & 0.245 \\
\hline
\end{tabular}

Table 4

\begin{tabular}{lccl}
\hline & Barcelona1 & E-25 & Meridiana \\
\hline$\mu_{\mathrm{w}}$ & 0.044 & 0.024 & 0.008
\end{tabular}

Table 5

\begin{tabular}{cll}
\hline Barcelona1 & E-25 & Meridiana \\
\hline $20.5 \%$ & $24.2 \%$ & $21.4 \%$
\end{tabular}




\section{Annexes}

In the following tables, full experimental information is reported.

The first column indicates approaching flow; the second and third columns stand, respectively, for transversal and longitudinal slopes; the fourth column represents the intercepted flow; the fifth column reports flow levels upstream the grates, the sixth column contains cross sectionally averaged velocity values and the last column contains top width values.

Barcelona1

In the following table, experimental information used to obtain the relationship presented in this paper is reported.

\begin{tabular}{|c|c|c|c|c|c|c|}
\hline $\mathbf{Q}[\mathbf{L} / \mathbf{s}]$ & Ix [\%] & Iy [\%] & Qintercepted $[\mathrm{m} 3 / \mathbf{s}]$ & $\mathbf{y}[\mathbf{m}]$ & $\mathbf{V}[\mathbf{m} / \mathbf{s}]$ & $\mathbf{W}[\mathbf{m}]$ \\
\hline 200 & $0 \%$ & $2 \%$ & 0.020 & 0.046 & 1.449 & 3.00 \\
\hline 200 & $0 \%$ & 2 & 0.015 & 0.030 & 2.222 & 3.00 \\
\hline 200 & $0 \%$ & $8 \%$ & 0.013 & 0.027 & 2.469 & 3.00 \\
\hline 200 & $0 \%$ & $10 \%$ & 0.013 & 0.025 & 2.667 & 3.00 \\
\hline 200 & $2 \%$ & $2 \%$ & 0.034 & 0.075 & 1.481 & 3.00 \\
\hline 200 & $2 \%$ & $8 \%$ & 0.022 & 0.046 & 3.781 & 2.30 \\
\hline 200 & $2 \%$ & $10 \%$ & 0.020 & 0.045 & 3.951 & 2.25 \\
\hline 200 & $4 \%$ & $1 \%$ & 0.047 & 0.106 & 1.641 & 2.65 \\
\hline 200 & $4 \%$ & $2 \%$ & 0.047 & 0.104 & 1.479 & 2.60 \\
\hline 200 & $4 \%$ & $4 \%$ & 0.042 & 0.098 & 1.666 & 2.45 \\
\hline 200 & $4 \%$ & $10 \%$ & 0.030 & 0.070 & 3.265 & 1.75 \\
\hline 150 & $0 \%$ & $8 \%$ & 0.012 & 0.027 & 1.852 & 3.00 \\
\hline 150 & $0 \%$ & $10 \%$ & 0.012 & 0.025 & 2.000 & 3.00 \\
\hline 150 & $2 \%$ & $2 \%$ & 0.029 & 0.066 & 1.377 & 3.00 \\
\hline 150 & $2 \%$ & $6 \%$ & 0.022 & 0.052 & 2.219 & 2.60 \\
\hline 150 & $2 \%$ & $10 \%$ & 0.019 & 0.044 & 3.099 & 2.20 \\
\hline 150 & $4 \%$ & $1 \%$ & 0.045 & 0.106 & 1.068 & 2.65 \\
\hline 150 & $4 \%$ & $2 \%$ & 0.044 & 0.094 & 1.358 & 2.35 \\
\hline 150 & $4 \%$ & $6 \%$ & 0.030 & 0.074 & 2.191 & 1.85 \\
\hline 150 & $4 \%$ & $8 \%$ & 0.027 & 0.072 & 2.315 & 1.80 \\
\hline 150 & $4 \%$ & $10 \%$ & 0.026 & 0.069 & 2.520 & 1.73 \\
\hline 100 & $2 \%$ & $6 \%$ & 0.018 & 0.042 & 2.268 & 2.10 \\
\hline 100 & $2 \%$ & $8 \%$ & 0.017 & 0.037 & 2.922 & 1.85 \\
\hline 100 & $4 \%$ & $1 \%$ & 0.037 & 0.092 & 0.945 & 2.30 \\
\hline 100 & $4 \%$ & $4 \%$ & 0.031 & 0.074 & 1.461 & 1.85 \\
\hline 100 & $4 \%$ & $6 \%$ & 0.027 & 0.062 & 2.081 & 1.55 \\
\hline 100 & $4 \%$ & $8 \%$ & 0.024 & 0.059 & 2.298 & 1.48 \\
\hline 100 & $4 \%$ & $10 \%$ & 0.023 & 0.057 & 2.462 & 1.43 \\
\hline 50 & $2 \%$ & $4 \%$ & 0.016 & 0.036 & 1.543 & 1.80 \\
\hline 50 & $2 \%$ & $6 \%$ & 0.015 & 0.033 & 1.837 & 1.65 \\
\hline 50 & $2 \%$ & $8 \%$ & 0.014 & 0.031 & 2.081 & 1.55 \\
\hline 50 & $2 \%$ & $10 \%$ & 0.013 & 0.029 & 2.378 & 1.45 \\
\hline 50 & $4 \%$ & $6 \%$ & 0.023 & 0.053 & 1.424 & 1.33 \\
\hline 50 & $4 \%$ & $10 \%$ & 0.020 & 0.047 & 1.811 & 1.18 \\
\hline 25 & $4 \%$ & $6 \%$ & 0.017 & 0.042 & 1.134 & 1.05 \\
\hline
\end{tabular}




\begin{tabular}{|r|r|r|r|r|r|r|}
25 & $4 \%$ & $8 \%$ & 0.016 & 0.040 & 1.250 & 1.00 \\
\hline 25 & $4 \%$ & $10 \%$ & 0.016 & 0.037 & 1.461 & 0.93 \\
\hline
\end{tabular}

In the following table, experimental information used to validate the relationship presented in this paper is reported.

\begin{tabular}{|r|r|r|r|r|r|r|}
\hline \multicolumn{1}{|l|}{$\mathbf{Q}[\mathbf{L} / \mathbf{s}]$} & $\mathbf{I x}[\mathbf{\%}]$ & \multicolumn{1}{l}{$\mathbf{l}$ [\%] } & Qintercepted [m3/s] & $\mathbf{y}[\mathbf{m}]$ & $\mathbf{V}[\mathbf{m} / \mathbf{s}]$ & $\mathbf{W}[\mathbf{m}]$ \\
\hline 200 & $0 \%$ & $4 \%$ & 0.019 & 0.044 & 1.515 & 3.00 \\
\hline 200 & $2 \%$ & $1 \%$ & 0.036 & 0.080 & 1.333 & 3.00 \\
\hline 200 & $2 \%$ & $4 \%$ & 0.031 & 0.065 & 1.758 & 3.25 \\
\hline 200 & $2 \%$ & $6 \%$ & 0.026 & 0.058 & 2.378 & 2.90 \\
\hline 200 & $4 \%$ & $6 \%$ & 0.037 & 0.090 & 1.975 & 2.25 \\
\hline 200 & $4 \%$ & $8 \%$ & 0.033 & 0.074 & 2.922 & 1.85 \\
\hline 150 & $0 \%$ & $6 \%$ & 0.013 & 0.029 & 1.724 & 3.00 \\
\hline 150 & $2 \%$ & $4 \%$ & 0.023 & 0.056 & 1.913 & 2.80 \\
\hline 150 & $2 \%$ & $8 \%$ & 0.02 & 0.048 & 2.604 & 2.40 \\
\hline 150 & $4 \%$ & $4 \%$ & 0.035 & 0.080 & 1.875 & 2.00 \\
\hline 100 & $2 \%$ & $2 \%$ & 0.022 & 0.055 & 1.322 & 2.75 \\
\hline 100 & $2 \%$ & $4 \%$ & 0.02 & 0.047 & 1.811 & 2.35 \\
\hline 100 & $2 \%$ & $10 \%$ & 0.016 & 0.034 & 3.460 & 1.70 \\
\hline 100 & $4 \%$ & $2 \%$ & 0.037 & 0.086 & 1.082 & 2.15 \\
\hline 50 & $4 \%$ & $4 \%$ & 0.026 & 0.058 & 1.189 & 1.45 \\
\hline 50 & $4 \%$ & $8 \%$ & 0.021 & 0.049 & 1.666 & 1.23 \\
\hline 25 & $4 \%$ & $4 \%$ & 0.016 & 0.043 & 1.082 & 1.08 \\
\hline
\end{tabular}

Meridiana

In the following table, experimental information used to obtain the relationship presented in this paper is reported.

\begin{tabular}{|r|r|r|r|r|r|r|}
\hline \multicolumn{1}{|l|}{$\mathbf{Q}[\mathbf{L} / \mathbf{s}]$} & \multicolumn{1}{l|}{$\mathbf{I x}[\mathbf{\%}]$} & Qintercepted $\mathbf{m} \mathbf{m} / \mathbf{s}]$ & $\mathbf{y}[\mathbf{m}]$ & $\mathbf{V}[\mathbf{m} / \mathbf{s}]$ & $\mathbf{W}[\mathbf{m}]$ \\
\hline 200 & $0 \%$ & $2 \%$ & 0.017 & 0.037 & 1.802 & 3.00 \\
\hline 200 & $0 \%$ & $4 \%$ & 0.015 & 0.032 & 2.083 & 3.00 \\
\hline 200 & $0 \%$ & $6 \%$ & 0.014 & 0.028 & 2.381 & 3.00 \\
\hline 200 & $0 \%$ & $10 \%$ & 0.013 & 0.026 & 2.564 & 3.00 \\
\hline 200 & $2 \%$ & $1 \%$ & 0.031 & 0.072 & 1.587 & 3.00 \\
\hline 200 & $2 \%$ & $8 \%$ & 0.022 & 0.045 & 3.951 & 2.25 \\
\hline 200 & $4 \%$ & $1 \%$ & 0.059 & 0.145 & 0.784 & 3.00 \\
\hline 200 & $4 \%$ & $1 \%$ & 0.049 & 0.110 & 1.322 & 2.75 \\
\hline 200 & $4 \%$ & $2 \%$ & 0.042 & 0.097 & 1.700 & 2.43 \\
\hline 200 & $4 \%$ & $6 \%$ & 0.028 & 0.067 & 3.564 & 1.68 \\
\hline 200 & $4 \%$ & $8 \%$ & 0.026 & 0.067 & 3.564 & 1.68 \\
\hline 150 & $0 \%$ & $6 \%$ & 0.012 & 0.023 & 2.174 & 3.00 \\
\hline 150 & $0 \%$ & $10 \%$ & 0.01 & 0.020 & 2.500 & 3.00 \\
\hline 150 & $2 \%$ & $2 \%$ & 0.025 & 0.055 & 1.983 & 2.75 \\
\hline 150 & $2 \%$ & $6 \%$ & 0.018 & 0.040 & 3.750 & 2.00 \\
\hline
\end{tabular}




\begin{tabular}{|r|r|r|r|r|r|r|}
\hline 150 & $2 \%$ & $8 \%$ & 0.018 & 0.038 & 4.155 & 1.90 \\
\hline 150 & $2 \%$ & $10 \%$ & 0.018 & 0.035 & 4.898 & 1.75 \\
\hline 150 & $4 \%$ & $2 \%$ & 0.037 & 0.087 & 1.585 & 2.18 \\
\hline 150 & $4 \%$ & $6 \%$ & 0.026 & 0.062 & 3.122 & 1.55 \\
\hline 150 & $4 \%$ & $10 \%$ & 0.022 & 0.052 & 4.438 & 1.30 \\
\hline 100 & $2 \%$ & $2 \%$ & 0.018 & 0.048 & 1.736 & 2.40 \\
\hline 100 & $2 \%$ & $4 \%$ & 0.017 & 0.038 & 2.770 & 1.90 \\
\hline 100 & $2 \%$ & $6 \%$ & 0.016 & 0.035 & 3.265 & 1.75 \\
\hline 100 & $2 \%$ & $10 \%$ & 0.015 & 0.028 & 5.102 & 1.40 \\
\hline 100 & $4 \%$ & $1 \%$ & 0.035 & 0.097 & 0.850 & 2.43 \\
\hline 100 & $4 \%$ & $6 \%$ & 0.022 & 0.054 & 2.743 & 1.35 \\
\hline 100 & $4 \%$ & $10 \%$ & 0.02 & 0.047 & 3.622 & 1.18 \\
\hline 50 & $2 \%$ & $4 \%$ & 0.013 & 0.027 & 2.743 & 1.35 \\
\hline 50 & $2 \%$ & $6 \%$ & 0.012 & 0.024 & 3.472 & 1.20 \\
\hline 50 & $2 \%$ & $10 \%$ & 0.011 & 0.021 & 4.535 & 1.05 \\
\hline 50 & $4 \%$ & $4 \%$ & 0.021 & 0.047 & 1.811 & 1.18 \\
\hline 50 & $4 \%$ & $6 \%$ & 0.019 & 0.042 & 2.268 & 1.05 \\
\hline 50 & $4 \%$ & $10 \%$ & 0.017 & 0.036 & 3.086 & 0.90 \\
\hline
\end{tabular}

In the following table, experimental information used to validate the relationship presented in this paper is reported.

\begin{tabular}{|r|r|r|r|r|r|r|}
\hline Q [L/s] & Ix [\%] & \multicolumn{1}{l|}{ ly [\%] } & Qintercepted [m3/s] & $\mathbf{y}[\mathbf{m}]$ & $\mathbf{V}[\mathbf{m} / \mathbf{s}]$ & $\mathbf{W}$ [m] \\
\hline 200 & $0 \%$ & $8 \%$ & 0.013 & 0.027 & 2.469 & 3.00 \\
\hline 200 & $2 \%$ & $2 \%$ & 0.028 & 0.058 & 2.378 & 2.90 \\
\hline 200 & $2 \%$ & $4 \%$ & 0.024 & 0.052 & 2.959 & 2.60 \\
\hline 200 & $2 \%$ & $6 \%$ & 0.023 & 0.048 & 3.472 & 2.40 \\
\hline 200 & $2 \%$ & $10 \%$ & 0.022 & 0.042 & 4.535 & 2.10 \\
\hline 200 & $4 \%$ & $4 \%$ & 0.033 & 0.073 & 3.002 & 1.83 \\
\hline 200 & $4 \%$ & $10 \%$ & 0.025 & 0.060 & 4.444 & 1.50 \\
\hline 150 & $0 \%$ & $8 \%$ & 0.011 & 0.021 & 2.381 & 3.00 \\
\hline 150 & $2 \%$ & $4 \%$ & 0.020 & 0.046 & 2.836 & 2.30 \\
\hline 150 & $4 \%$ & $1 \%$ & 0.042 & 0.100 & 1.200 & 2.50 \\
\hline 150 & $4 \%$ & $4 \%$ & 0.030 & 0.070 & 2.449 & 1.75 \\
\hline 150 & $4 \%$ & $8 \%$ & 0.024 & 0.057 & 3.693 & 1.43 \\
\hline 100 & $2 \%$ & $8 \%$ & 0.015 & 0.032 & 3.906 & 1.60 \\
\hline 100 & $4 \%$ & $2 \%$ & 0.032 & 0.075 & 1.422 & 1.88 \\
\hline 100 & $4 \%$ & $4 \%$ & 0.025 & 0.061 & 2.150 & 1.53 \\
\hline 100 & $4 \%$ & $8 \%$ & 0.021 & 0.050 & 3.200 & 1.25 \\
\hline 50 & $2 \%$ & $8 \%$ & 0.012 & 0.022 & 4.132 & 1.10 \\
\hline 50 & $4 \%$ & $8 \%$ & 0.018 & 0.038 & 2.770 & 0.95 \\
\hline
\end{tabular}

\section{E-25}

In the following table, experimental information used to obtain the relationship presented in this paper is reported.

\begin{tabular}{|l|l|l|l|l|l|l|}
\hline Q [L/s] & Ix [\%] & Iy [\%] & Qintercepted [m3/s] & y [m] & V [m/s] & W [m] \\
\hline
\end{tabular}




\begin{tabular}{|c|c|c|c|c|c|c|}
\hline 215 & $0 \%$ & $4 \%$ & 0.018 & 0.038 & 1.886 & 3.00 \\
\hline 215 & $0 \%$ & $6 \%$ & 0.017 & 0.034 & 2.108 & 3.00 \\
\hline 215 & $0 \%$ & $10 \%$ & 0.015 & 0.027 & 2.654 & 3.00 \\
\hline 215 & $2 \%$ & $1 \%$ & 0.041 & 0.085 & 1.303 & 3.00 \\
\hline 215 & $2 \%$ & $2 \%$ & 0.034 & 0.074 & 1.629 & 3.00 \\
\hline 215 & $2 \%$ & $4 \%$ & 0.029 & 0.056 & 2.742 & 2.80 \\
\hline 215 & $2 \%$ & $8 \%$ & 0.025 & 0.050 & 3.440 & 2.50 \\
\hline 215 & $2 \%$ & $10 \%$ & 0.024 & 0.045 & 4.247 & 2.25 \\
\hline 215 & $4 \%$ & $1 \%$ & 0.057 & 0.120 & 1.194 & 3.00 \\
\hline 215 & $4 \%$ & $1 \%$ & 0.053 & 0.135 & 0.956 & 3.00 \\
\hline 215 & $4 \%$ & $2 \%$ & 0.049 & 0.100 & 1.720 & 2.50 \\
\hline 215 & $4 \%$ & $4 \%$ & 0.042 & 0.085 & 2.381 & 2.13 \\
\hline 215 & $4 \%$ & $6 \%$ & 0.037 & 0.072 & 3.318 & 1.80 \\
\hline 150 & $0 \%$ & $8 \%$ & 0.013 & 0.023 & 2.174 & 3.00 \\
\hline 150 & $0 \%$ & $10 \%$ & 0.012 & 0.020 & 2.500 & 3.00 \\
\hline 150 & $2 \%$ & $2 \%$ & 0.029 & 0.064 & 1.471 & 3.00 \\
\hline 150 & $2 \%$ & $6 \%$ & 0.023 & 0.045 & 2.963 & 2.25 \\
\hline 150 & $4 \%$ & $1 \%$ & 0.048 & 0.115 & 0.907 & 2.88 \\
\hline 150 & $4 \%$ & $1 \%$ & 0.046 & 0.122 & 0.806 & 3.00 \\
\hline 150 & $4 \%$ & $4 \%$ & 0.037 & 0.075 & 2.133 & 1.88 \\
\hline 150 & $4 \%$ & $6 \%$ & 0.033 & 0.065 & 2.840 & 1.63 \\
\hline 150 & $4 \%$ & $8 \%$ & 20 & 0.060 & 3.333 & 1.50 \\
\hline 150 & $4 \%$ & $10 \%$ & 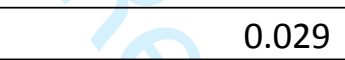 & 0.055 & 3.967 & 1.38 \\
\hline 100 & $2 \%$ & $8 \%$ & 0.018 & 0.034 & 3.460 & 1.70 \\
\hline 100 & $2 \%$ & $10 \%$ & 0.017 & 0.030 & 4.444 & 1.50 \\
\hline 100 & $4 \%$ & $2 \%$ & 0.035 & 0.082 & 1.190 & 2.05 \\
\hline 100 & $4 \%$ & $4 \%$ & 0.033 & 0.068 & 1.730 & 1.70 \\
\hline 100 & $4 \%$ & $8 \%$ & 0.027 & 0.053 & 2.848 & 1.33 \\
\hline 100 & $4 \%$ & $10 \%$ & 0.026 & 0.050 & 3.200 & 1.25 \\
\hline 50 & $4 \%$ & $2 \%$ & 0.027 & 0.069 & 0.840 & 1.73 \\
\hline 50 & $4 \%$ & $4 \%$ & 0.026 & 0.053 & 1.424 & 1.33 \\
\hline 50 & $4 \%$ & $6 \%$ & 0.024 & 0.047 & 1.811 & 1.18 \\
\hline 50 & $4 \%$ & $10 \%$ & 0.020 & 0.037 & 2.922 & 0.93 \\
\hline
\end{tabular}

In the following table, experimental information used to validate the relationship presented in this paper is reported.

\begin{tabular}{|r|r|r|r|r|r|r|}
\hline \multicolumn{1}{|l|}{$\mathbf{Q}[\mathbf{L} / \mathbf{s}]$} & $\mathbf{I x}[\mathbf{\%}]$ & \multicolumn{1}{l|}{$\mathbf{l}[\mathbf{\%}]$} & Qintercepted $[\mathbf{m} \mathbf{3} / \mathbf{s}]$ & $\mathbf{y}[\mathbf{m}]$ & $\mathbf{V}[\mathbf{m} / \mathbf{s}]$ & $\mathbf{W}[\mathbf{m}]$ \\
\hline 215 & $0 \%$ & $8 \%$ & 0.016 & 0.030 & 2.389 & 3.00 \\
\hline 215 & $2 \%$ & $1 \%$ & 0.044 & 0.120 & 0.796 & 3.00 \\
\hline 215 & $2 \%$ & $6 \%$ & 0.026 & 0.053 & 3.062 & 2.65 \\
\hline 215 & $4 \%$ & $8 \%$ & 0.034 & 0.068 & 3.720 & 1.70 \\
\hline 215 & $4 \%$ & $10 \%$ & 0.033 & 0.065 & 4.071 & 1.63 \\
\hline 150 & $2 \%$ & $1 \%$ & 0.039 & 0.090 & 0.833 & 3.00 \\
\hline 150 & $2 \%$ & $1 \%$ & 0.034 & 0.075 & 1.111 & 3.00 \\
\hline 150 & $2 \%$ & $4 \%$ & 0.024 & 0.047 & 2.716 & 2.35 \\
\hline 150 & $2 \%$ & $8 \%$ & 0.022 & 0.040 & 3.750 & 2.00 \\
\hline
\end{tabular}




\begin{tabular}{|r|r|r|r|r|r|r|}
\hline 150 & $2 \%$ & $10 \%$ & 0.020 & 0.038 & 4.155 & 1.90 \\
\hline 150 & $4 \%$ & $2 \%$ & 0.043 & 0.090 & 1.481 & 2.25 \\
\hline 100 & $2 \%$ & $6 \%$ & 0.019 & 0.038 & 2.770 & 1.90 \\
\hline 100 & $4 \%$ & $1 \%$ & 0.039 & 0.108 & 0.686 & 2.70 \\
\hline 100 & $4 \%$ & $1 \%$ & 0.038 & 0.093 & 0.925 & 2.33 \\
\hline 100 & $4 \%$ & $6 \%$ & 0.029 & 0.056 & 2.551 & 1.40 \\
\hline 50 & $4 \%$ & $8 \%$ & 0.021 & 0.043 & 2.163 & 1.08 \\
\hline
\end{tabular}




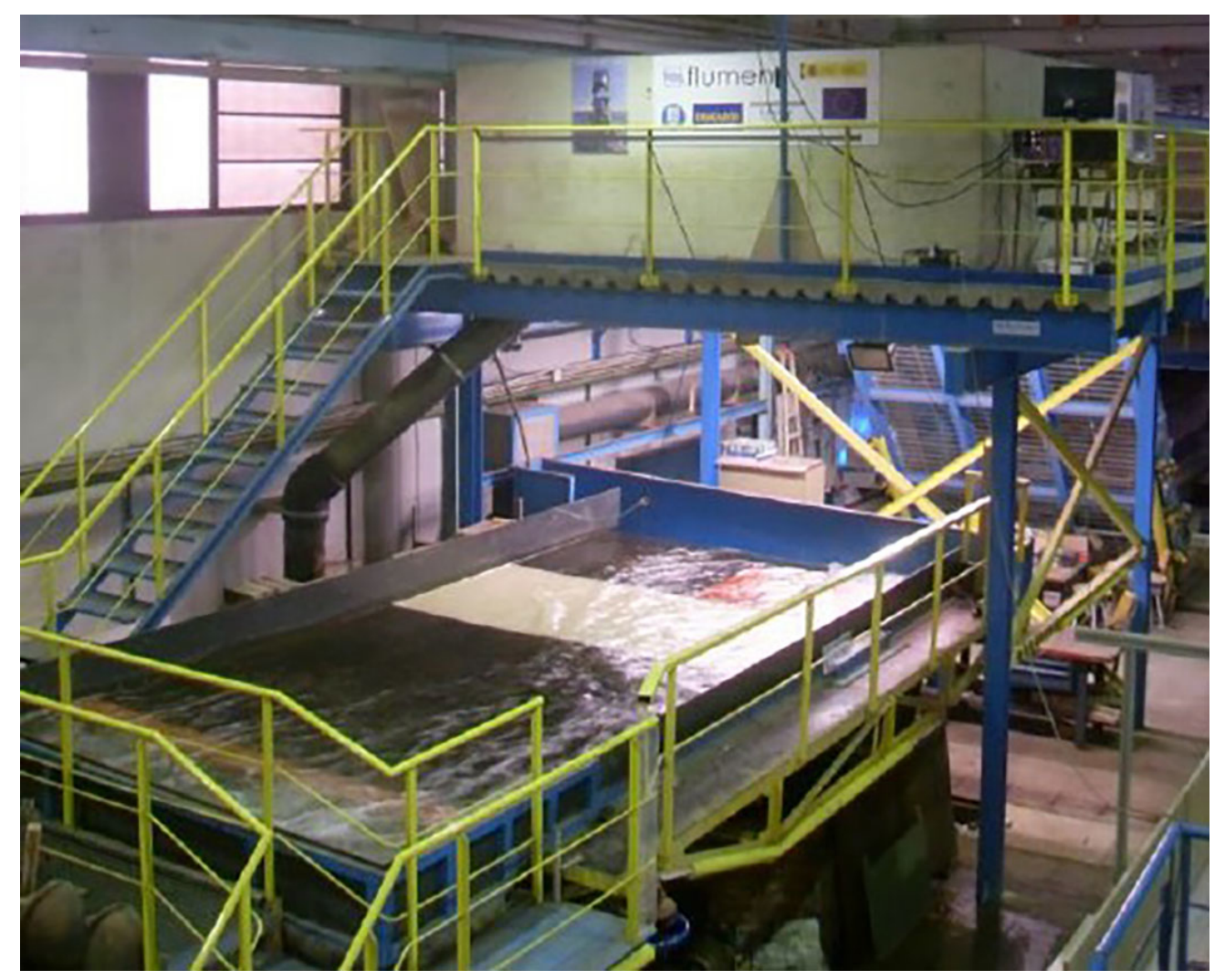

Figure 1: Experimental equipment

$90 \times 72 \mathrm{~mm}(300 \times 300$ DPI $)$ 


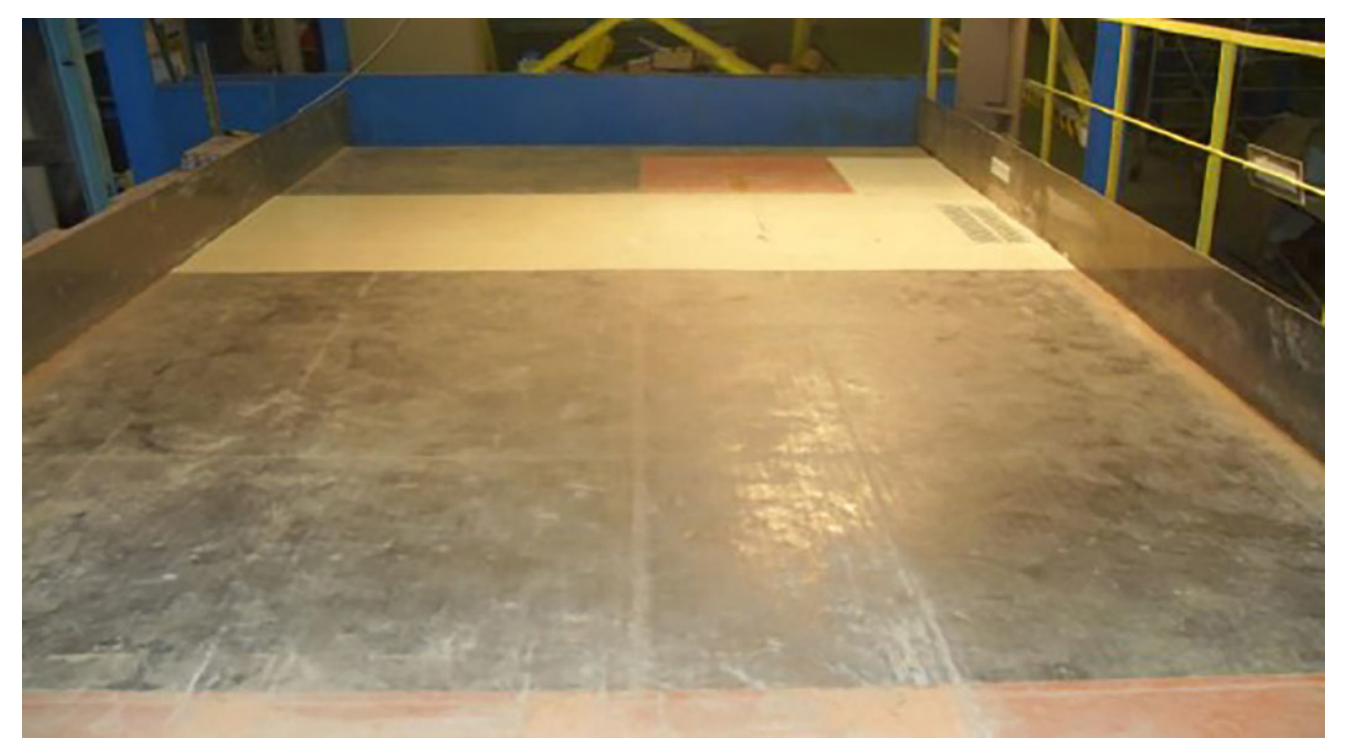

Figure 2: Useful area of the metallic platform $90 \times 49 \mathrm{~mm}(300 \times 300 \mathrm{DPI})$ 

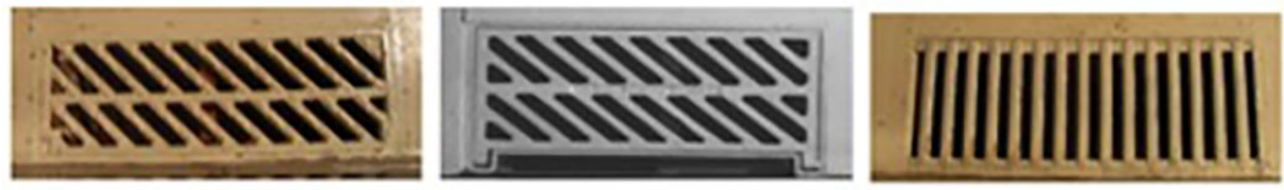

Figure 3: Grates models: Barcelona1 (left), E-25 (center), Meridiana (right)

$90 \times 14 \mathrm{~mm}(300 \times 300 \mathrm{DPI})$ 


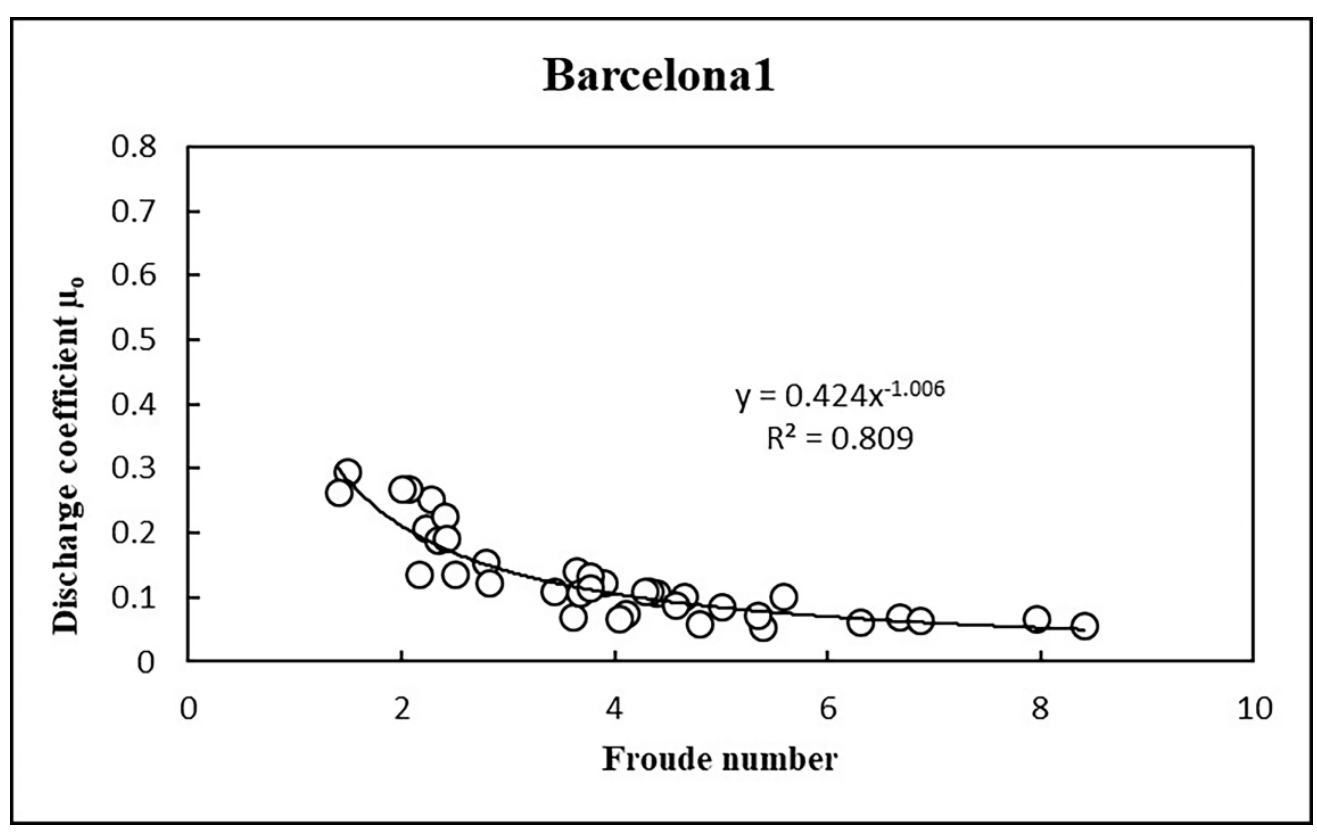

Figure 4: Discharge coefficients for grate Barcelona1 with orifice approach $89 \times 55 \mathrm{~mm}(1000 \times 1000 \mathrm{DPI})$ 


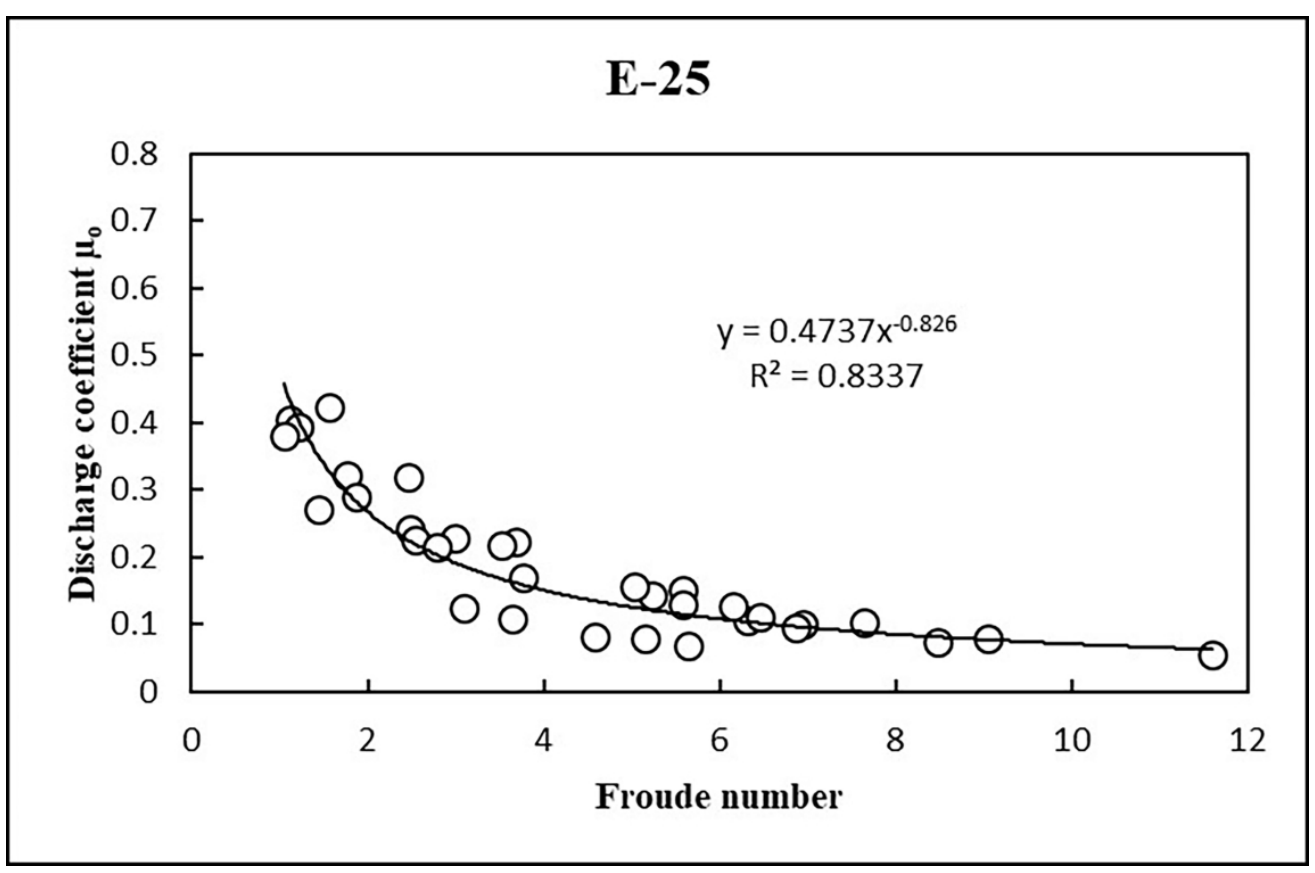

Figure 5: Discharge coefficients for grate E-25 with orifice approach

$89 \times 58 \mathrm{~mm}(1000 \times 1000 \mathrm{DPI})$ 


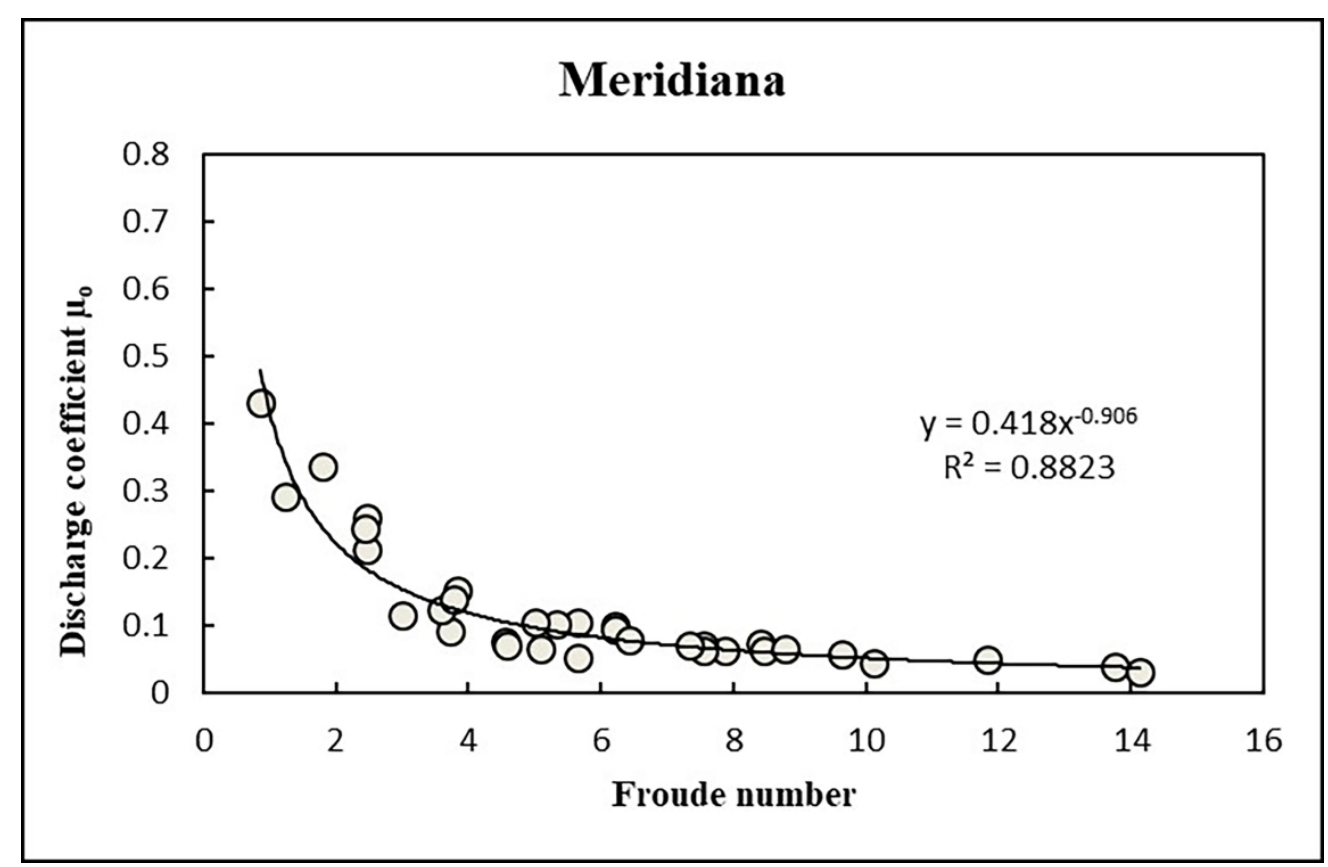

Figure 6: Discharge coefficients for grate Meridiana with orifice approach $89 \times 58 \mathrm{~mm}(1000 \times 1000$ DPI $)$ 

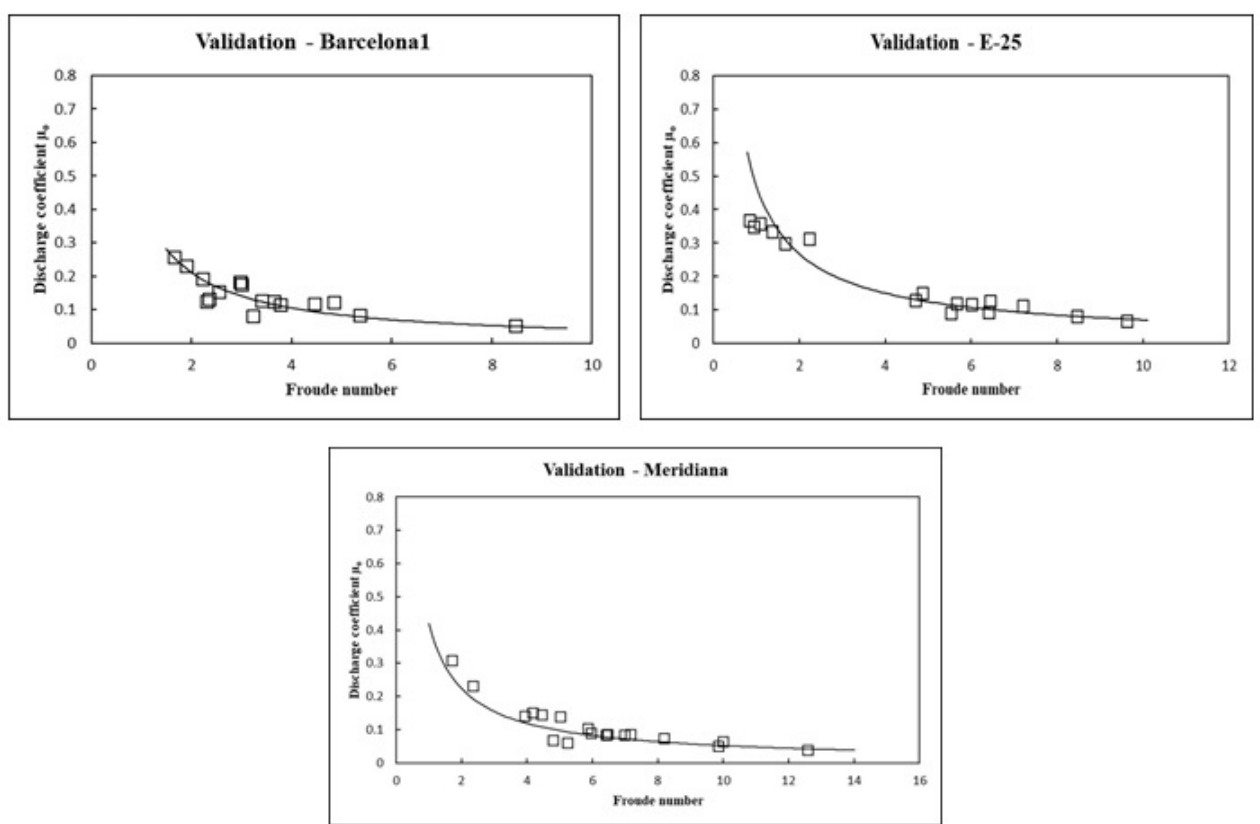

Figure 7: Validation for discharge coefficients with orifice approach $191 \times 135 \mathrm{~mm}(96 \times 96$ DPI) 


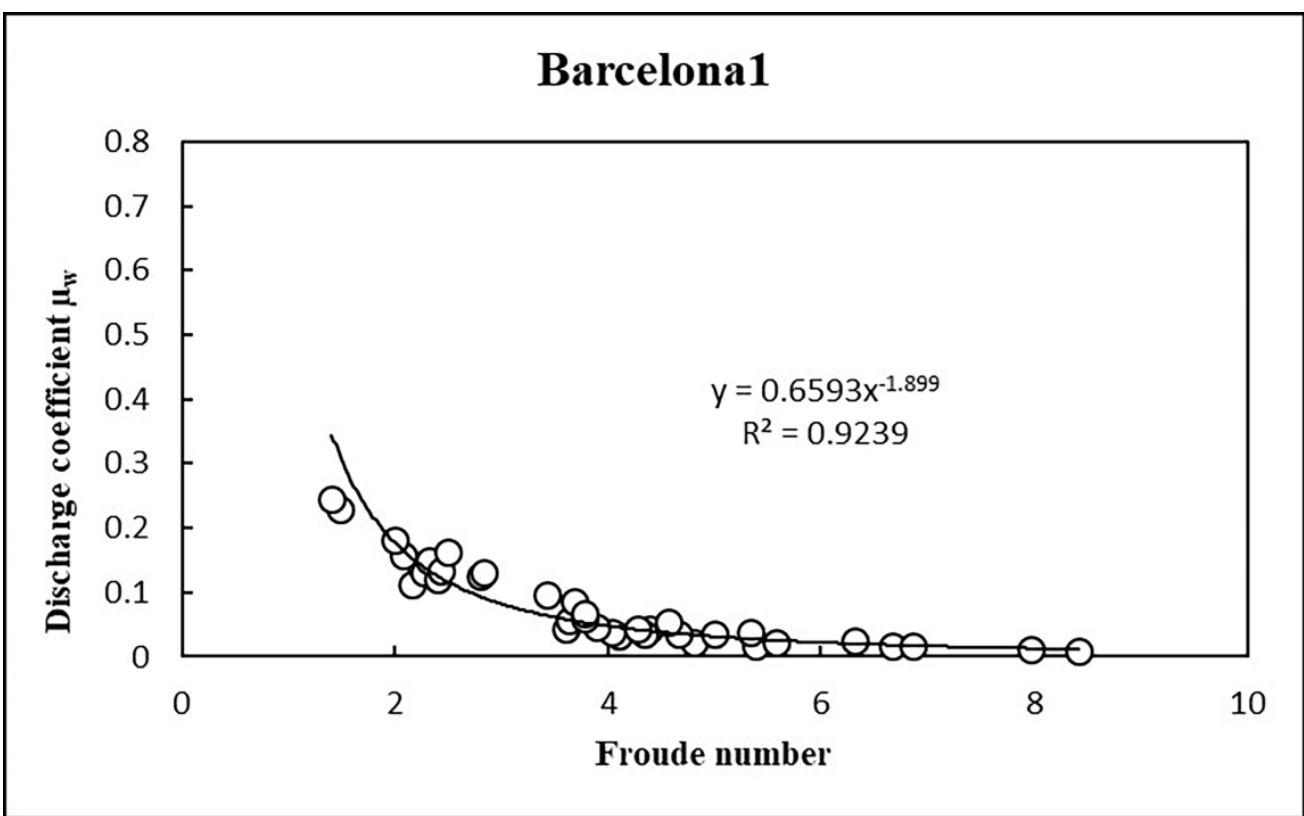

Figure 8: Discharge coefficients for grate Barcelona1 with weir approach

$89 \times 55 \mathrm{~mm}(1000 \times 1000$ DPI $)$ 


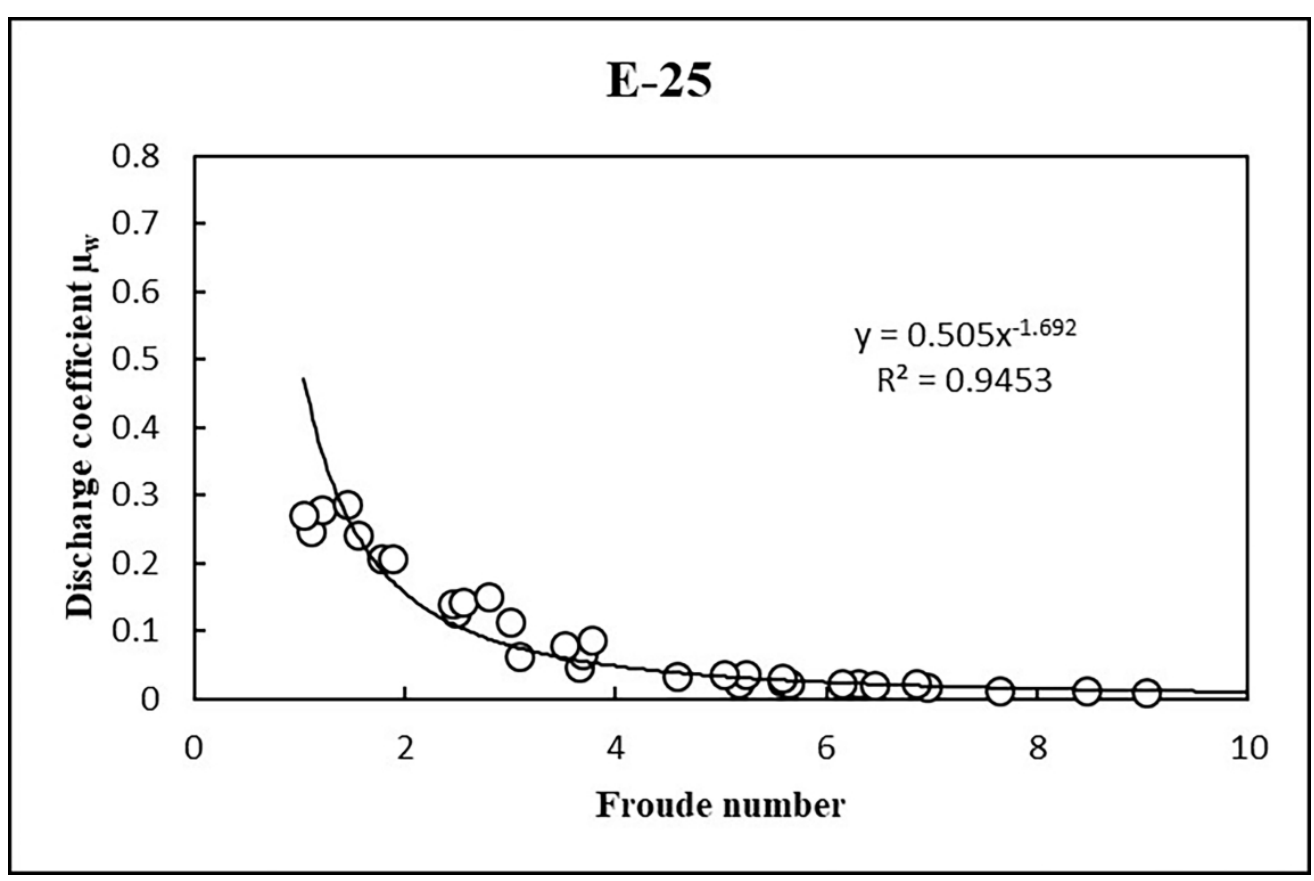

Figure 9: Discharge coefficients for grate E-25 with weir approach

$89 \times 59 \mathrm{~mm}(1000 \times 1000$ DPI $)$ 
Figure 10: Discharge coefficients for grate Meridiana with weir approach

$89 \times 58 \mathrm{~mm}(1000 \times 1000 \mathrm{DPI})$

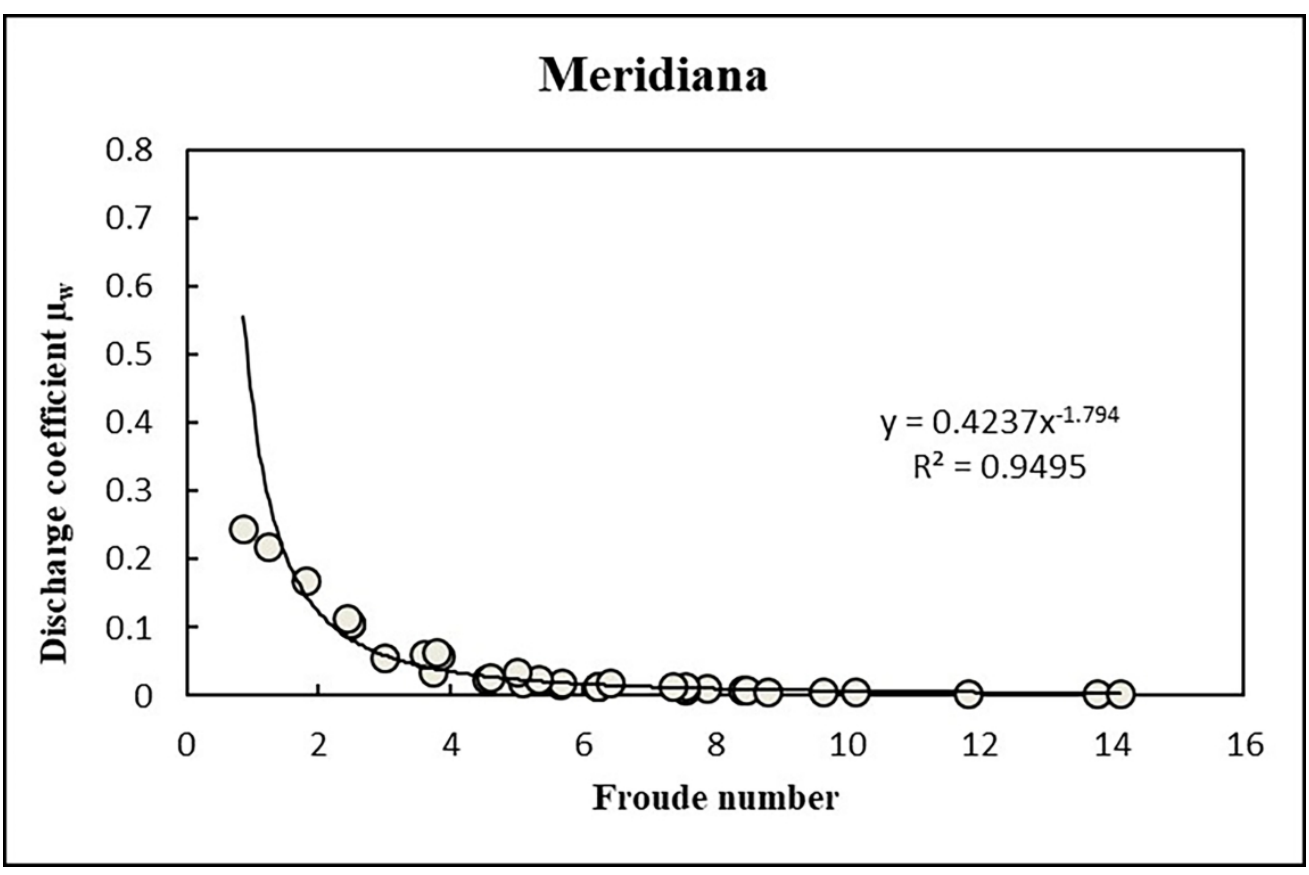



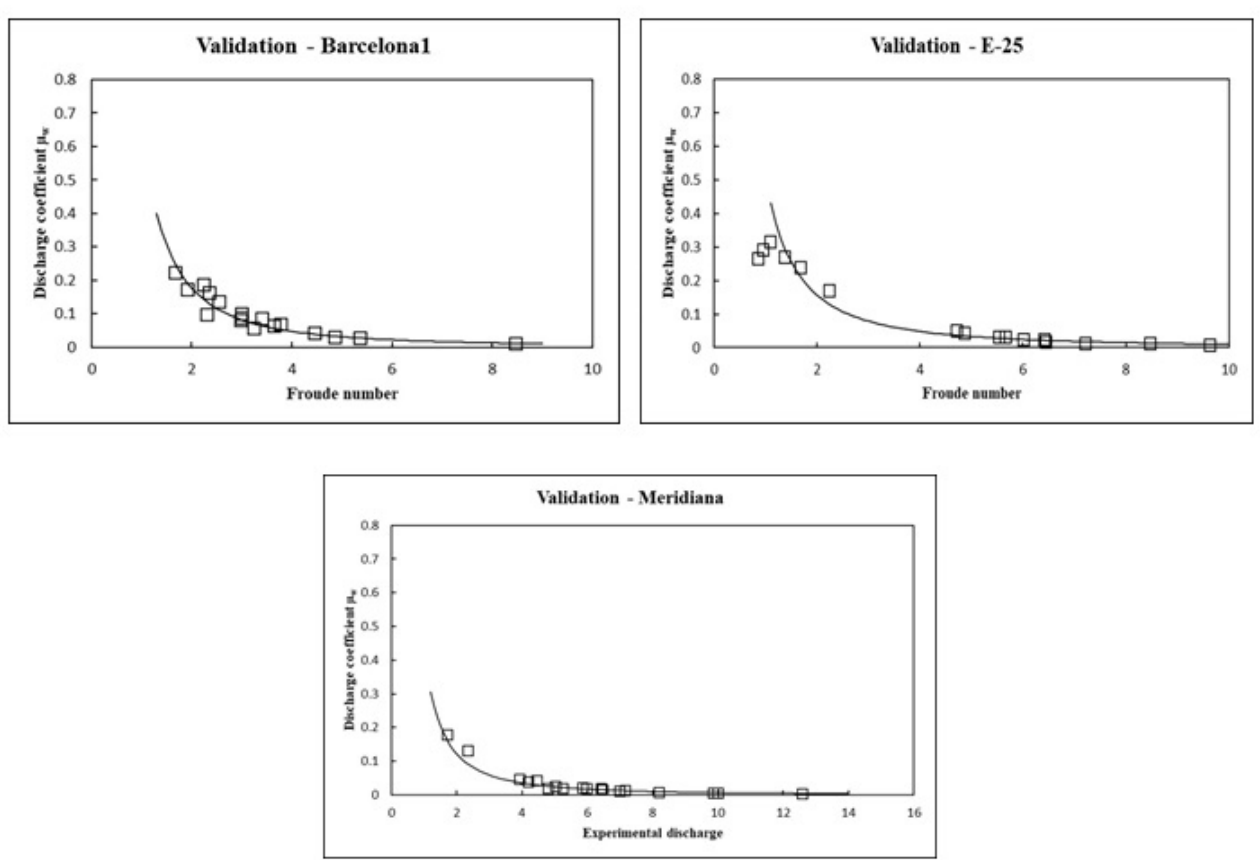

Figure 11: Validation for potential correlation with weir approach

$191 \times 135 \mathrm{~mm}(96 \times 96$ DPI $)$ 